\title{
Activities of daily living as an additional predictor of complications and outcomes in elderly patients with acute myocardial infarction
}

This article was published in the following Dove Press journal:

Clinical Interventions in Aging

24 August 2016

Number of times this article has been viewed

\author{
Hiroyuki Nakajima' \\ Jiro Yoshioka ${ }^{2}$ \\ Nobuyuki Totsuka² \\ Izumi Miyazawa ${ }^{2}$ \\ Tatsuya Usui \\ Nobuyuki Urasawa ${ }^{2}$ \\ Takahiro Kobayashi ${ }^{3}$ \\ Tomoaki Mochidome ${ }^{4}$ \\ 'Department of Cardiology, Nagano \\ Matsushiro General Hospital, \\ ${ }^{2}$ Department of Cardiology, Nagano \\ Red Cross Hospital, ${ }^{3}$ Department \\ of Cardiology, Nagano Municipal \\ Hospital, Nagano, ${ }^{4}$ Department of \\ Cardiovascular Medicine, Shinshu \\ University School of Medicine, \\ Matsumoto, Japan
}

Background: Age is an important determinant of outcome in acute myocardial infarction (AMI). However, in clinical settings, there is an occasional mismatch between chronological age and physical age. We evaluated whether activities of daily living (ADL), which reflect physical age, also predict complications and prognosis in elderly patients with AMI.

Design: Single-center, observational, and retrospective cohort study.

Methods: Preserved ADL and low ADL were defined according to the scale for independence degree of daily living for the disabled elderly by the Japanese Ministry of Health, Labour, and Welfare. We examined 82 consecutive patients aged $\geq 75$ years with AMI who underwent primary percutaneous coronary intervention. Patients were divided into preserved ADL ( $\mathrm{n}=52$; mean age, $81.8 \pm 4.8$ years; male, $59.6 \%$ ) and low ADL ( $\mathrm{n}=30$; mean age, $85.8 \pm 4.7$ years; male, $40.0 \%$ ) groups according to prehospital ADL.

Results: The prevalence of Killip class II-IV and in-hospital mortality rate were significantly higher with low ADL compared to that with preserved ADL ( $23.1 \%$ vs $60.0 \%, P=0.0019 ; 5.8 \%$ vs $30.0 \%, P=0.0068$, respectively). Multivariate analysis showed that ADL was an independent predictor of Killip class II-IV and 1-year mortality after adjusting for age, sex, and other possible confounders (odds ratio 5.11, 95\% confidence interval [CI] 1.52-17.2, $P=0.0083$; hazard ratio $4.32,95 \%$ CI $1.31-14.3, P=0.017$, respectively).

Conclusion: Prehospital ADL is a significant predictor of heart failure complications and prognosis in elderly patients with AMI undergoing primary percutaneous coronary intervention, irrespective of age and sex.

Keywords: acute myocardial infarction, activities of daily living, disability, Killip classification, primary percutaneous coronary intervention

\section{Background}

Population aging has progressed worldwide, remarkably so in Japan where there is a high increase in the proportion of people $\geq 75$ years old. ${ }^{1}$ The number of elderly people with low activities of daily living (ADL; eg, those requiring nursing care) has recently increased. More than $20 \%$ of Japanese people $\geq 75$ years old have received certification of a need for long-term care from the government. ${ }^{2}$

Human aging often entails conditions such as frailty and disability for a while before death $^{3}$ but varies widely between individuals. This variation is based on the physical age relative to chronological age. Frailty is considered to pose a risk of disability and adverse health outcome. Several reports demonstrated frailty as a predictor of adverse outcome in cardiovascular diseases. ${ }^{4}$ Disabilities were broadly defined as dependency in performing ADL. Some epidemiologic studies showed that ADL predict mortality in
Correspondence: Hiroyuki Nakajima Department of Cardiology, Nagano Matsushiro General Hospital,

183 Matsushiro, Matsushiromachi, Nagano City 38I-I23I, Japan

$\mathrm{Tel}+8 \mid 26278203$ I

Fax +8I 262789167

Email nhiroyukil I@live.jp 
the elderly population. ${ }^{5,6}$ Moreover, disability is also related to incidence of coronary heart disease. ${ }^{7}$

The current American College of Cardiology/American Heart Association (ACC/AHA) guidelines underscore the need to consider geriatric conditions for care and outcomes in elderly patients with acute myocardial infarction (AMI). ${ }^{8,9}$ Patient age is an important determinant of outcome in AMI; it carries high weightage in scales such as the thrombolysis in myocardial infarction (TIMI) score and Grace score, which are AMI risk classifications. ${ }^{8-12}$ However, geriatric conditions are not usually considered when calculating such scores. Clinically, there is an occasional mismatch between chronological age and physical age.

Because of population aging, elderly AMI patients with disabilities are no longer rare. The clinical impact of ADL disability on complications and outcomes of acute diseases, such as AMI, has not been systematically studied, because older adults with disability are rarely represented in clinical trials or studies. In the present study, we focused on physical age based on ADL levels and aimed to assess whether prehospital ADL could predict complications and outcomes in elderly patients with AMI, with the aim of developing better care and management.

\section{Methods}

\section{Study design and patient population}

This was a single-center, observational, and retrospective cohort study designed to investigate the clinical impact of ADL on complications and outcomes of AMI in elderly patients ( $\geq 75$ years old). We retrospectively reviewed patient records and collected in-hospital and 1-year survival data. The study subjects were 82 consecutive patients $\geq 75$ years old with AMI who underwent primary percutaneous coronary intervention (PCI) in Nagano Red Cross Hospital from August 2011 to March 2014. All admitted patients were evaluated for prehospital ADL according to the scale for independence degree of daily living for the disabled elderly by the Japanese Ministry of Health, Labour, and Welfare (Table 1). This scale is used in Japan in association with governmental long-term care insurance. The ADL survey is based on interviews of patients or their families.

Preserved ADL was defined as not requiring any assistance or nursing care (Rank J), and low ADL was defined as requiring any assistance or nursing care (Ranks $\mathrm{A}-\mathrm{C}$ ) in daily life before admission. The patients were divided into preserved ADL $(\mathrm{n}=52)$ and low ADL $(\mathrm{n}=30)$ groups according to ADL survey results on admission. Patients with post coronary artery bypass grafting, definite or probable stent thrombosis, or cardiopulmonary arrest were excluded. All
Table I Independence degree of daily living for the disabled elderly

\begin{tabular}{|c|c|c|}
\hline \multirow[t]{3}{*}{$\begin{array}{l}\text { Self- } \\
\text { supported }\end{array}$} & Rank J & $\begin{array}{l}\text { Some disabilities, but daily living is } \\
\text { mostly independent; capable of going } \\
\text { outdoors unassisted. }\end{array}$ \\
\hline & 1 & $\begin{array}{l}\text { Goes outdoors with means of } \\
\text { transportation, etc. }\end{array}$ \\
\hline & 2 & Goes out near home. \\
\hline \multirow[t]{3}{*}{$\begin{array}{l}\text { Quasi- } \\
\text { bedridden }\end{array}$} & Rank A & $\begin{array}{l}\text { Indoor living predominantly } \\
\text { independent, but unable to go out } \\
\text { without assistance. }\end{array}$ \\
\hline & 1 & $\begin{array}{l}\text { Goes out with assistance, spending most } \\
\text { of the time during the daytime out of bed. }\end{array}$ \\
\hline & 2 & $\begin{array}{l}\text { Does not go out frequently, repeating } \\
\text { cycles of lying down on and getting up } \\
\text { from the bed during the daytime. }\end{array}$ \\
\hline \multirow[t]{6}{*}{ Bedridden } & Rank B & $\begin{array}{l}\text { Some assistance needed for indoor living, } \\
\text { also lies in bed for much of the daytime, } \\
\text { although sitting position is possible. }\end{array}$ \\
\hline & I & $\begin{array}{l}\text { Uses a wheelchair without assistance, takes } \\
\text { meals, and excretes/urinates off the bed. }\end{array}$ \\
\hline & 2 & Uses a wheelchair with assistance. \\
\hline & Rank C & $\begin{array}{l}\text { Bedridden all day, requires assistance } \\
\text { with excretion/urination, meals, and } \\
\text { dressing/undressing. }\end{array}$ \\
\hline & 1 & Capable of changing posture in bed. \\
\hline & 2 & $\begin{array}{l}\text { Unable to change posture in bed without } \\
\text { assistance. }\end{array}$ \\
\hline
\end{tabular}

Note: Prehospital ADL was evaluated according to the scale for independence degree of daily living for the disabled elderly by the Japanese Ministry of Health, Labour, and Welfare based on interviews.

Abbreviation: $A D L$, activities of daily living.

study participants provided written informed consent and the study design was developed in accordance with the Declaration of Helsinki and approved by the ethics committee at Nagano Red Cross Hospital.

\section{Definition}

AMI included ST-segment elevation myocardial infarction (STEMI) and non-STEMI and was diagnosed according to the AHA/ACC guidelines. ${ }^{13}$ The Killip classification is a clinical scale to stratify the severity of heart failure (HF). Patients in Killip class I demonstrated no evidence of HF. Patients in Killip class II had findings consistent with mildto-moderate HF. Patients in Killip class III demonstrated overt pulmonary edema, and patients in Killip class IV were in cardiogenic shock. ${ }^{14}$ Diabetes was defined as glycosylated hemoglobin $\geq 6.5 \%$, treatment with oral hypoglycemic agents, or treatment with insulin injection. Hypertension was defined as systolic blood pressure $\geq 18.7 \mathrm{kPa}$, diastolic blood pressure $\geq 12.0 \mathrm{kPa}$, or ongoing treatment for hypertension. Dyslipidemia was defined as a serum total cholesterol concentration $\geq 5.7 \mathrm{mmol} / \mathrm{L}$, low-density lipoprotein cholesterol concentration $\geq 3.6 \mathrm{mmol} / \mathrm{L}$, or ongoing lipid-lowering therapy. Body mass index (BMI) was defined as weight 
in kilograms divided by the square of height in meters. HF history was based on a previous diagnosis of HF. Multivessel disease was defined as the presence of $\geq 75 \%$ lesions in $\geq 2$ major coronary arteries on coronary angiography.

\section{Data analysis}

All statistical analyses were performed with EZR Version 1.21. ${ }^{15}$ Continuous variables are reported as mean \pm standard deviation. Categorical variables are reported as frequencies and percentages. Patient characteristics of both groups were compared using Fisher's exact test. Continuous variables were compared using the Student's $t$-test. Multivariate logistic regression analysis and Cox proportional hazards model were used to adjust for the effects of ADL on Killip classification and mortality within 1 year. $P<0.05$ was considered statistically significant in all analyses.

\section{Results}

\section{Patient characteristics}

Patient characteristics are shown in Table 2. Of the 82 patients $\geq 75$ years old, $52(63.4 \%)$ and 30 (36.6\%) were categorized into the preserved and low ADL groups, respectively. The low ADL group was significantly older and had a stronger stroke history. Prevalence of major risk factors for

Table 2 Patient characteristics

\begin{tabular}{|c|c|c|c|c|}
\hline & Overall & $\begin{array}{l}\text { Preserved } \\
\text { ADL }\end{array}$ & $\begin{array}{l}\text { Low } \\
\text { ADL }\end{array}$ & $P$-value \\
\hline $\mathrm{n}$ & 82 & 52 & 30 & \\
\hline Mean age $\pm S D$ (years) & $83.3 \pm 5.1$ & $81.8 \pm 4.8$ & $85.8 \pm 4.7$ & $<0.001$ \\
\hline Male (\%) & 52.4 & 59.6 & 40.0 & 0.14 \\
\hline BMI $\left(\mathrm{kg} / \mathrm{m}^{2}\right) \pm \mathrm{SD}$ & $22.0 \pm 3.2$ & $22.6 \pm 2.5$ & $21.0 \pm 3.9$ & 0.028 \\
\hline Hypertension (\%) & 74.4 & 76.9 & 70.0 & 0.67 \\
\hline Dyslipidemia (\%) & 40.2 & 40.4 & 40.0 & 1.0 \\
\hline Diabetes (\%) & 34.1 & 30.8 & 40.0 & 0.54 \\
\hline Current smoker (\%) & 6.1 & 9.6 & 0 & 0.16 \\
\hline Previous smoker (\%) & 34.1 & 44.2 & 16.7 & 0.027 \\
\hline Previous MI (\%) & 6.1 & 7.7 & 3.3 & 0.75 \\
\hline Previous stroke (\%) & 20.7 & I I.5 & 36.7 & 0.016 \\
\hline History of HF (\%) & 3.7 & 1.9 & 6.7 & 0.62 \\
\hline Atrial fibrillation (\%) & 15.9 & 17.3 & 13.3 & 0.87 \\
\hline Hemoglobin $(g / L)$ & $0.130 \pm 0.019$ & $0.135 \pm 0.016$ & $0.121 \pm 0.019$ & $<0.001$ \\
\hline Albumin $(g / L)$ & $39 \pm 4$ & $40 \pm 3$ & $37 \pm 4$ & 0.0032 \\
\hline eGFR $\left(\mathrm{mL} / \mathrm{min} / \mathrm{I} .73 \mathrm{~m}^{2}\right)$ & $53.6 \pm 17.6$ & $56.5 \pm 17.5$ & $48.7 \pm 16.8$ & 0.054 \\
\hline Triglyceride (mmol/L) & $0.93 \pm 0.54$ & $0.89 \pm 0.40$ & $0.97 \pm 0.76$ & 0.53 \\
\hline HDL-C (mmol/L) & $1.3 \pm 0.3$ & $1.3 \pm 0.3$ & $1.2 \pm 0.3$ & 0.69 \\
\hline LDL-C (mmol/L) & $2.6 \pm 0.7$ & $2.8 \pm 0.6$ & $2.4 \pm 0.9$ & 0.06 \\
\hline EPA/AA & $0.47 \pm 0.41$ & $0.50 \pm 0.50$ & $0.4 I \pm 0.20$ & 0.41 \\
\hline HbAlc (\%) & $6.3 \pm 1.2$ & $6.2 \pm 1.0$ & $6.5 \pm 1.5$ & 0.23 \\
\hline
\end{tabular}

Note: Data presented as mean \pm SD unless stated otherwise.

Abbreviations: $A D L$, activities of daily living; BMI, body mass index; MI, myocardial infarction; HF, heart failure; eGFR, estimated glomerular filtration rate; HDL-C, high-density lipoprotein cholesterol; LDL-C, low-density lipoprotein cholesterol; EPA, eicosapentaenoic acid; AA, arachidonic acid; HbAlc, glycosylated hemoglobin; $\mathrm{SD}$, standard deviation. arteriosclerosis (hypertension, dyslipidemia, and diabetes) was not significantly different among groups. History of cardiac diseases, such as HF, atrial fibrillation, and myocardial infarction, was also not significantly different. The patients in the low ADL group differed in BMI, hemoglobin concentration, and serum albumin level.

\section{Clinical presentation}

The principal conditions of AMI are shown in Table 3. There were no significant differences between the preserved and low ADL groups with respect to the rate of STEMI, the culprit vessel, coronary artery complexity (prevalence of multivessel diseases and SYNTAX score),${ }^{16}$ door-to-balloon time, and symptom-onset-to-balloon time. However, the low ADL group included more cases with a higher Killip class than the preserved ADL group (Killip class II-IV, $23.1 \%$ vs $60.0 \%$, $P=0.0019$, Figure 1). In-hospital mortality rate was significantly higher in the low ADL group than in the preserved ADL group (5.8\% vs $30.0 \%, P=0.0068$, Figure 2$)$. All-cause death occurred in four (7.7\%) patients and $13(43.4 \%)$ patients in the preserved and low ADL groups, respectively. KaplanMeier curve analysis revealed that 1-year all-cause mortality was significantly higher in the low ADL group (Figure 3).

\section{Regression analysis}

Multivariate logistic regression analysis showed that ADL was an independent predictor of HF complications (Killip

Table 3 Principal conditions of acute myocardial infarction

\begin{tabular}{|c|c|c|c|c|}
\hline Condition & Overall & $\begin{array}{l}\text { Preserved } \\
\text { ADL }\end{array}$ & $\begin{array}{l}\text { Low } \\
\text { ADL }\end{array}$ & $P$-value \\
\hline$n$ & 82 & 52 & 30 & \\
\hline STEMI (\%) & 81.7 & 80.8 & 83.3 & 1.0 \\
\hline \multicolumn{5}{|c|}{ Symptom-onset-to-balloon time } \\
\hline $0-4.5$ hours (\%) & 40.2 & 42.3 & 36.7 & 0.65 \\
\hline$>4.5-12$ hours $(\%)$ & 31.7 & 28.8 & 36.7 & 0.47 \\
\hline $\begin{array}{l}>12 \text { hours or } \\
\text { unknown (\%) }\end{array}$ & 28.0 & 28.8 & 26.7 & 1.0 \\
\hline $\begin{array}{l}\text { Door-to-balloon-time } \\
\text { (minutes) }\end{array}$ & $122 \pm 100$ & $117 \pm 88$ & $132 \pm 120$ & 0.54 \\
\hline SYNTAX score & $14.5 \pm 7.7$ & $|4.5 \pm 8|$. & $14.4 \pm 7.0$ & 0.98 \\
\hline \multicolumn{5}{|l|}{ Culprit vessels } \\
\hline LAD (\%) & 53.7 & 50.0 & 60.0 & 0.49 \\
\hline LCx or RCA (\%) & 43.9 & 48.1 & 36.7 & 0.36 \\
\hline LMT (\%) & 2.4 & 1.9 & 3.3 & 1.0 \\
\hline Multivessel diseases (\%) & 39.0 & 36.5 & 43.3 & 0.71 \\
\hline Peak CK ( $\mu$ kat/L) & $37.8 \pm 33.4$ & $36.3 \pm 29.8$ & $40.4 \pm 39.3$ & 0.60 \\
\hline TIMI3 achievement (\%) & 81.7 & 88.5 & 70.0 & 0.074 \\
\hline Single stenting (\%) & 62.2 & 57.7 & 70.0 & 0.35 \\
\hline Multiple stenting (\%) & 28.0 & 32.7 & 20.0 & 0.31 \\
\hline Other procedure (\%) & 9.8 & 9.6 & 10.0 & 1.0 \\
\hline
\end{tabular}

Note: Data presented as mean \pm standard deviation unless stated otherwise. Abbreviations: ADL, activities of daily living; STEMI, ST-segment elevation myocardial infarction; LAD, left anterior descending artery; LCx, left circumflex artery; RCA, right coronary artery; LMT, left main trunk; CK, creatine kinase; TIMI3, thrombolysis in myocardial infarction-3 score. 


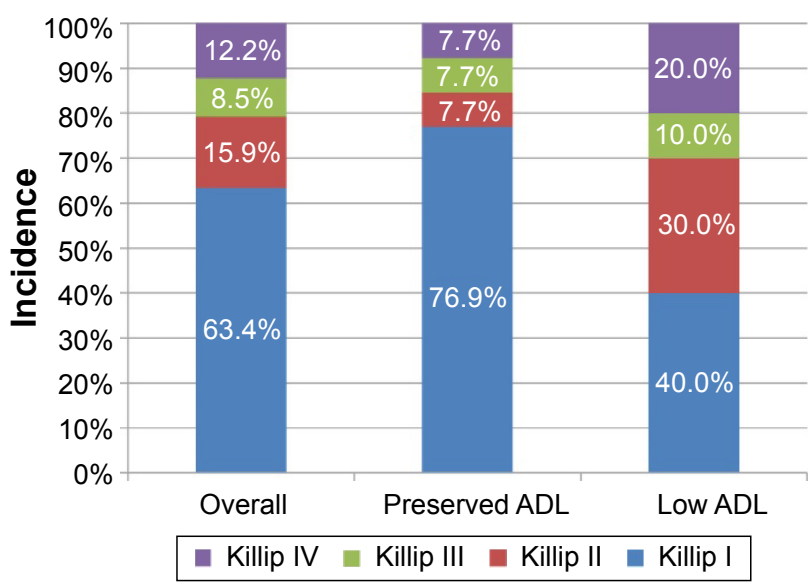

Figure I Distribution of Killip classification.

Note: The incidence of Killip class II-IV was significantly higher in the low ADL group than the preserved $A D L$ group $(23.1 \%$ vs $60.0 \%, P=0.0019)$.

Abbreviation: ADL, activities of daily living.

class II-IV). Similarly, the Cox hazard regression model revealed that $\mathrm{ADL}$ was an independent predictor of 1-year mortality (Table 4). Possible confounders that were considered included age, sex, estimated glomerular filtration rate (eGFR), SYNTAX score, symptom-onset-to-balloon time, history of atrial fibrillation, HF, and myocardial infarction in both analyses. We selected generally known factors affecting high Killip class and prognosis as specified variables in the multivariate model from previous studies. ${ }^{11,12,14}$

Differences in previous stroke history, BMI, anemia, and hypoalbuminemia were significant, but these factors contributed to low ADL and reflected low ADL; therefore, we considered them as intervening factors rather than confounding factors in the multivariate model.

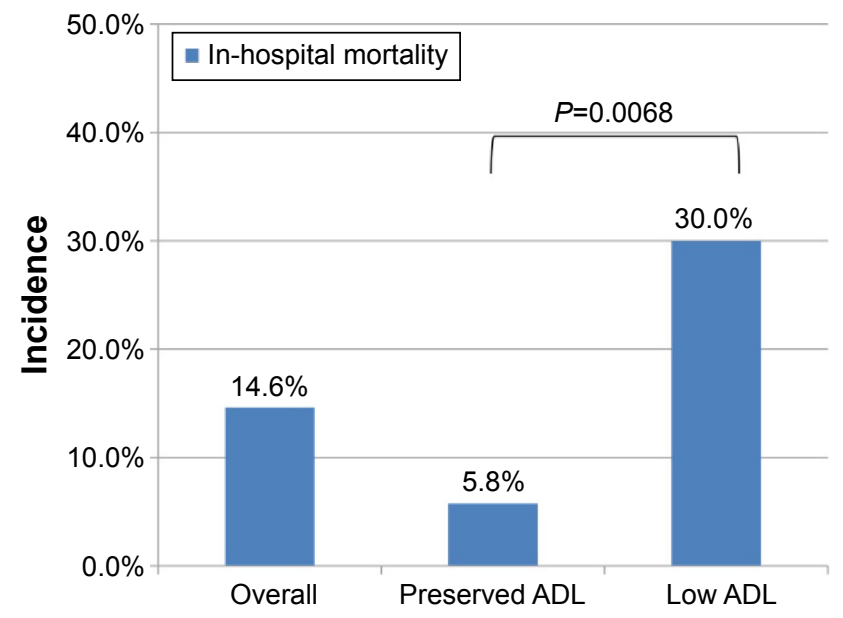

Figure $\mathbf{2}$ In-hospital mortality rate.

Note: In-hospital mortality rate was significantly higher in the low ADL group than the preserved ADL group (5.8\% vs $30.0 \%, P=0.0068$ ).

Abbreviation: ADL, activities of daily living.

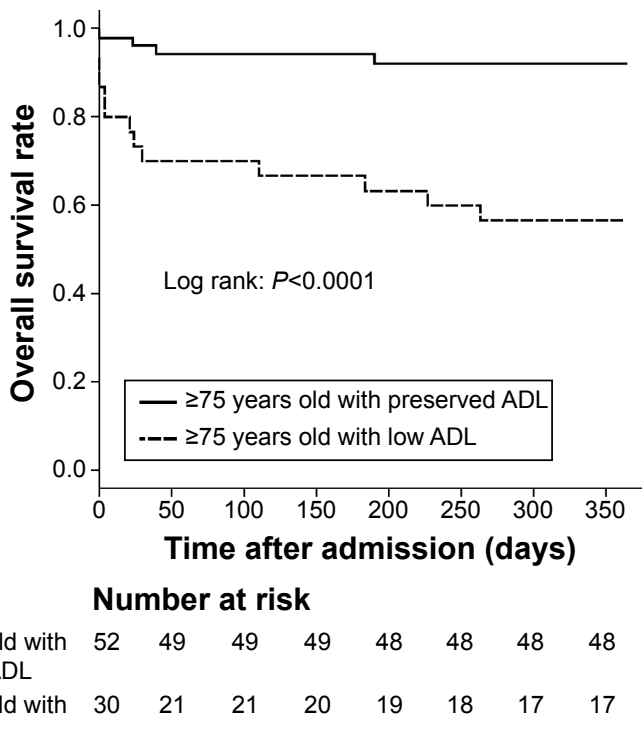

Figure 3 Kaplan-Meier curves of survival for patients $\geq 75$ years old with preserved ADL (preserved ADL group) and low ADL (low ADL group).

Note: The incidence of all-cause death within I year was significantly higher in the low $A D L$ group $(7.7 \%$ vs $43.4 \%, P<0.000$ I).

Abbreviation: $A D L$, activities of daily living.

\section{Discussion}

In this study, we recognized the importance of geriatric conditions, such as disability, and demonstrated that prehospital ADL, reflecting physical age, were a significant predictor of HF complications and prognosis in elderly AMI patients, irrespective of age and sex. Additionally, those with low ADL had a higher incidence of HF complications (Killip class II-IV) and poorer prognosis than those with preserved ADL.

In the study period, patients $\geq 75$ years old accounted for $42.9 \%$ of all AMI patients who underwent primary PCI in Nagano Red Cross Hospital. This is a high percentage compared to that in Western countries because of remarkable population aging in Japan. ${ }^{8,9,17,18}$ In the present study, we focused on not only elderly patients but also those with low ADL, who have not often been enrolled in clinical trials or studies.

Patient age is an important determinant of outcome. However, a meta-analysis revealed that reduction in the mortality and morbidity by primary PCI was independent of patient age in STEMI. ${ }^{19}$ Savonitto et $\mathrm{al}^{20}$ reported that early invasive treatment for elderly patients was beneficial in non-ST-segment elevation acute coronary syndrome with elevated troponin levels. Therefore, primary PCI for elderly STEMI or non-STEMI patients was considered a reasonable and feasible procedure. In the absence of any particular reason or contraindication, primary PCI and early reperfusion are the first-line treatment choice for AMI, even for elderly patients. 
Table 4 Univariate and multivariate analysis

\begin{tabular}{|c|c|c|c|c|c|c|}
\hline \multirow[t]{2}{*}{ Outcome (\%) } & \multirow{2}{*}{$\begin{array}{l}\text { Preserved } \\
\text { ADL }(n=52)\end{array}$} & \multirow{2}{*}{$\begin{array}{l}\text { Low } \\
\text { ADL }(n=30)\end{array}$} & \multicolumn{2}{|l|}{ Unadjusted } & \multicolumn{2}{|l|}{ Adjusted $^{a}$} \\
\hline & & & OR (95\% Cl) & $P$-value & OR (95\% CI) & $P$-value \\
\hline \multirow[t]{2}{*}{ Killip class II-IV } & 23.1 & 60.0 & $5.00(1.89-13.2)$ & 0.0012 & $5.11(1.52-17.2)$ & 0.0083 \\
\hline & & & HR (95\% Cl) & $P$-value & HR (95\% CI) & $P$-value \\
\hline All-cause mortality in I year & 7.7 & 43.3 & $6.99(2.28-21.5)$ & 0.00068 & $4.32(1.3 \mid-14.3)$ & 0.017 \\
\hline
\end{tabular}

Note: aConsidered confounders: age, sex, eGFR, SYNTAX score, symptom-onset-to-balloon time, history of myocardial infarction, HF, and atrial fibrillation.

Abbreviations: ADL, activities of daily living; OR, odds ratio; $\mathrm{Cl}$, confidence interval; HR, hazard ratio; eGFR, estimated glomerular filtration rate; $\mathrm{HF}$, heart failure.

Information about prognosis is essential for obtaining informed consent, especially in acute diseases requiring invasive therapy, such as AMI. The mortality of elderly patients with low ADL is substantially higher compared to the standard prognosis of AMI in Japan. ${ }^{21} \mathrm{HF}$ is one of the most common complications of AMI. The Killip classification is a simple clinical scale measuring severity of HF complications and is an important determinant of outcome in acute coronary syndrome. Generally, older patients have a higher incidence of HF complications (Killip class II-IV) than younger patients. ${ }^{14}$ We demonstrated that ADL also predicted HF complications (Killip class II-IV) in elderly patients. The low ADL group had high prevalence of prior HF, although this was not statistically significant due to the small size of the study. This may affect the higher incidence of Killip class II-IV in patients with low ADL. These findings regarding prognosis and HF complications are useful to obtain better informed consent when performing primary PCI; furthermore, they enable providers to provide careful management for elderly AMI patients, especially those with low ADL.

In our study, elderly patients with low ADL had a higher prevalence of stroke history than those with preserved ADL. Stroke history is not only one of the possible causes of ADL impairment but also a reflection of polyvascular diseases in elderly AMI patients. Patients with coronary artery diseases with one or more atherosclerotic lesions have a poor prognosis. ${ }^{22}$ Elderly patients with low ADL had a characteristic background related to aging, malnutrition, and frailty, such as low BMI, anemia, and hypoalbuminemia. Serum albumin level is an epidemiological predictor of adverse outcomes and mortality, not just in cardiovascular diseases. ${ }^{23,24}$ Anemia is a risk factor for cardiovascular disease outcome in the general population. ${ }^{25}$ Elderly patients with low ADL had lower eGFR, although without significance. Low eGFR has been widely known as a predictor of cardiovascular mortality. ${ }^{26}$

Although there were some differences in patient backgrounds among the groups, coronary artery complexity according to SYNTAX score and prevalence of multivessel disease were not significantly different, and we found it somewhat surprising that door-to-balloon and symptom-onset-to-balloon times were not significantly longer in elderly patients with low ADL. In primary PCI for both groups, the TIMI-3 score achievement rate tended to be lower in elderly patients with low ADL, but the difference was not significant. Moreover, in the PCI procedure, the rate of multiple stenting tended to be lower. Although further studies are needed, it is possible that conditions related to low ADL, such as delirium and communication difficulty, influenced the strategy and end point of PCI.

It is noteworthy that elderly patients $\geq 75$ years old with preserved ADL did not have worse prognosis and were not included in the higher incidence of HF complications (Killip class II-IV) when compared with other domestic reports, although they had a high mean age. ${ }^{21,27}$ This indicates that advanced age is not necessarily associated with poor prognosis and high incidence of HF complications in elderly AMI patients, especially with preserved ADL.

There are some standard scales to estimate ADL, such as the Barthel index, the Katz index, and the Stanford Health Assessment Questionnaire Disability. We used the independence degree of daily living for the disabled elderly as the ADL scale. This is one of the most widely used scales in Japan in association with long-term care insurance by the government and is more suitable for evaluating brief prehospital ADL, especially in emergency diseases, because of its simplicity of use.

In the present study, we focused on prehospital ADL. Some studies have reported that AMI contributes to declined independence and physical function in survivors. ${ }^{28,29}$ As disability itself is a predictor for mortality in an elderly population, ${ }^{5,6}$ it is possible that further ADL impairment after admission is also associated with poor prognosis in elderly patients with pre-existing low ADL. Therefore, ADL disability can be a vital factor for elderly patients with AMI both before and after admission.

\section{Conclusion}

Prehospital ADL, which reflects physical age, is a significant predictor of HF complications and prognosis in elderly 
patients with AMI undergoing primary PCI. In addition to chronological age, physical age based on ADL is an important factor in the management of AMI.

\section{Study limitations}

This study has several limitations. First, this was a singlecenter retrospective study and included a small number of patients. The ADL survey results were based on interviews, which thus may have been affected by individual subject variations. Therefore, there may be some bias in the patient population. Second, although ADL was the most important factor, the etiology of low ADL was not elucidated in this study. Third, mortality was composed of only all-cause mortality, and cardiac/noncardiac death was not differentiated.

\section{Acknowledgments}

Contents of this study were presented at The 64th Annual Scientific Session of the American College of Cardiology (ACC.15) on March 14-16, 2015, in San Diego, USA, and at The 80th Annual Scientific Meeting of the Japanese Circulation Society (JCS 2016) on March 18-20, 2016, in Sendai, Japan, as a poster.

\section{Disclosure}

The authors report no conflicts of interest in this work.

\section{References}

1. Cabinet Office, Government of Japan. Aging Society White Book. Tokyo: Cabinet Office, Government of Japan. 2015.

2. Ministry of Health, Labour and Welfare, Government of Japan. Report of Nursing Care-Insurance Service. Tokyo: Ministry of Health, Labour and Welfare, Government of Japan. 2013.

3. Singh M, Stewart R, White H. Importance of frailty in patients with cardiovascular disease. Eur Heart J. 2014;35(26):1726-1731.

4. Afilalo J, Alexander KP, Mack MJ, et al. Frailty assessment in the cardiovascular care of older adults. J Am Coll Cardiol. 2014;63(8):747-762.

5. Cesari M, Onder G, Zamboni V, et al. Physical function and self-rated health status as predictors of mortality: results from longitudinal analysis in the ilSIRENTE study. BMC Geriatr. 2008;8:34.

6. Nakazawa A, Nakamura K, Kitamura K, Yoshizawa Y. Association between activities of daily living and mortality among institutionalized elderly adults in Japan. J Epidemiol. 2012;22(6):501-507.

7. Plichart M, Barberger-Gateau P, Tzourio C, et al. Disability and incident coronary heart disease in older community-dwelling adults: the threecity study. J Am Geriatr Soc. 2010;58(4):636-642.

8. Alexander KP, Newby LK, Armstrong PW, et al. Acute coronary care in the elderly, part I. Circulation. 2007;115:2549-2569.

9. Alexander KP, Newby LK, Armstrong PW, et al. Acute coronary care in the elderly, part II. Circulation. 2007;115:2570-2589.

10. Halon DA, Adawi S, Dobrecky-Mery I, Lewis BS. Importance of increasing age on the presentation and outcome of acute coronary syndromes in elderly patients. J Am Coll Cardiol. 2004;43(3): $346-352$.
11. Morrow DA, Antman EM, Charlesworth A, et al. TIMI risk score for ST-elevation myocardial infarction: A convenient, bedside, clinical score for risk assessment at presentation: an intravenous nPA for treatment of infarcting myocardium early II trial substudy. Circulation. 2000;102:2031-2037.

12. Fox KA, Dabbous OH, Goldberg RJ, et al. Prediction of risk of death and myocardial infarction in the six months after presentation with acute coronary syndrome: prospective multinational observational study (GRACE). BMJ. 2006;333(7578):1091.

13. Thygesen K, Alpert JS, White HD; for Joint ESC/ACCF/AHA/WHF Task Force for the Redefinition of Myocardial Infarction. Universal definition of myocardial infarction. Circulation. 2007;116(22):2634-2653.

14. DeGeare VS, Boura JA, Grines LL, O’Neill WW, Grines CL. Predictive value of the Killip classification in patients undergoing primary percutaneous coronary intervention for acute myocardial infarction. Am J Cardiol. 2001;87(9):1035-1038.

15. Kanda Y. Investigation of the freely available easy-to-use software 'EZR' for medical statistics. Bone Marrow Transplant. 2013;48(3): 452-458.

16. Sianos G, Morel MA, Kappetein AP, et al. The SYNTAX Score: an angiographic tool grading the complexity of coronary artery disease. EuroIntervention. 2005;1(2):219-227.

17. Claessen BE, Kikkert WJ, Engstrom AE, et al. Primary percutaneous coronary intervention for ST elevation myocardial infarction in octogenarians: trends and outcomes. Heart. 2010;96(11):843-847.

18. Rosengren A, Wallentin L, Simoons M, et al. Age, clinical presentation, and outcome of acute coronary syndromes in the Euroheart acute coronary syndrome survey. Eur Heart J. 2006;27(7):789-795.

19. de Boer SP, Westerhout CM, Simes RJ, et al; for Primary Coronary Angioplasty Versus Thrombolysis-2 (PCAT-2) Trialists Collaborators Group. Mortality and morbidity reduction by primary percutaneous coronary intervention is independent of the patient's age. JACC Cardiovasc Interv. 2010;3(3):324-331.

20. Savonitto S, Cavallini C, Petronio AS, et al; for Italian Elderly ACS Trial Investigators. Early aggressive versus initially conservative treatment in elderly patients with non-ST-segment elevation acute coronary syndrome: a randomized controlled trial. JACC Cardiovasc Interv. 2012;5(9):906-916.

21. Daida $\mathrm{H}$, Miyauchi $\mathrm{K}$, Ogawa $\mathrm{H}$, et al; for PACIFIC Investigators. Management and two-year long-term clinical outcome of acute coronary syndrome in Japan: prevention of atherothrombotic incidents following ischemic coronary attack (PACIFIC) registry. Circ J. 2013;77(4): 934-943.

22. Bhatt DL, Eagle KA, Ohman EM, et al; for REACH Registry Investigators. Comparative determinants of 4-year cardiovascular event rates in stable outpatients at risk of or with atherothrombosis. JAMA. 2010; 304(12):1350-1357.

23. Corti MC, Guralnik JM, Salive ME, Sorkin JD. Serum albumin level and physical disability as predictors of mortality in older persons. JAMA. 1994;272(13):1036-1042.

24. Herrmann FR, Safran C, Levkoff SE, Minaker KL. Serum albumin level on admission as a predictor of death, length of stay, and readmission. Arch Intern Med. 1992;152(1):125-130.

25. Sarnak MJ, Tighiouart H, Manjunath G, et al. Anemia as a risk factor for cardiovascular disease in the Atherosclerosis Risk in Communities (ARIC) study. J Am Coll Cardiol. 2002;40(1):27-33.

26. Matsushita K, van der Velde M, Astor BC, et al; for Chronic Kidney Disease Prognosis Consortium. Association of estimated glomerular filtration rate and albuminuria with all-cause and cardiovascular mortality in general population cohorts: a collaborative meta-analysis. Lancet. 2010;375(9731):2073-2081.

27. Takii T, Yasuda S, Takahashi J, et al; for MIYAGI-AMI Study Investigators. Trends in acute myocardial infarction incidence and mortality over 30 years in Japan: report from the MIYAGI-AMI Registry Study. Circ J. 2010;74(1):93-100. 
28. Dodson JA, Arnold SV, Reid KJ, et al. Physical function and independence 1 year after myocardial infarction: observations from the translational research investigating underlying disparities in recovery from acute myocardial infarction: patients' health status registry. Am Heart J. 2012;163(5):790-796.
29. van Jaarsveld CH, Sanderman R, Miedema I, Ranchor AV, Kempen GI. Changes in health-related quality of life in older patients with acute myocardial infarction or congestive heart failure: a prospective study. $J$ Am Geriatr Soc. 2001;49(8):1052-1058.

\section{Publish your work in this journal}

Clinical Interventions in Aging is an international, peer-reviewed journal focusing on evidence-based reports on the value or lack thereof of treatments intended to prevent or delay the onset of maladaptive correlates of aging in human beings. This journal is indexed on PubMed Central, MedLine,

\section{Dovepress}

CAS, Scopus and the Elsevier Bibliographic databases. The manuscript management system is completely online and includes a very quick and fair peer-review system, which is all easy to use. Visit http://www.dovepress. $\mathrm{com} /$ testimonials.php to read real quotes from published authors. 